\title{
Man-Made:The damaging consequences of having so few women in positions of power
}

\author{
Eva Tutchell and John Edmonds
}

\begin{abstract}
Behind the surface issues of workplace innovation, structural change is needed. The UK is failing to benefit from the true innovative potential of women, to the detriment of business and political organisations. Despite rhetoric and legislation, inequality continues. Research for "Man-Made" (Tutchell and Edmonds; Farnham, Gower 2015) has shown that women are denied power. The article sets out an agenda for change.
\end{abstract}

Keywords: change, inequality, power, UK, women 


\section{Introduction}

Some politicians seem to forget the enthusiasms of their youth very quickly. Before he became Prime Minister, David Cameron talked as if he really cared about equal rights for women. As Leader of the Opposition, he said he was working hard to get more women into safe Conservative seats. As Prime Minister, he appointed Lord Mervyn Davies to lead a Government initiative to increase the number of women on the boards of large British companies. This enthusiasm seemed to infect his colleagues. Theresa May famously wore a tee shirt declaring, "This is what a feminist looks like".

After all the warm words and photo opportunities, not very much changed. Some commentators predicted that the 2015 General Election would transform the proportion of women MPs on the Conservative benches. It did not happen: there are still four male Conservative MPs for every Tory woman MP. The only major Party that does worse is the Liberal Democrats who have no women MPs at all. Meanwhile Lord Davies spent six years trying to persuade big companies to appoint more women as Non-Executive Directors. Eventually he reported that the proportion of women on FTSE100 Boards had touched 25\%. Is this a cause for rejoicing? As the authors of Man-Made, we find it difficult to raise even half a cheer. Women in the boardrooms of our largest 100 companies are still outnumbered by three to one. The next 250 companies have even fewer women on their boards and the record of smaller companies is abysmal.

When we started the research for Man-Made, our book about women and power, we thought that we might find a pattern of steady improvement. Like many people in Britain, we wanted to believe the optimistic stories about a host of women breaking through the glass ceiling into top positions. Instead, what we discovered was often disappointing and sometimes shocking. The contrast between those encouraging headlines and the reality is depressing. We found that Britain is an $80 / 20$ society: $80 \%$ of powerful positions are held by men and only $20 \%$ are held by women.

\section{Imbalance}

As part of our research for Man-Made we interviewed over a hundred successful women. We learnt that being outnumbered by men is part of their shared experience, particularly as they rise through the hierarchy. Many women employees work in the lower levels of most organisations but as successful women climb to each higher rung on the career ladder they find fewer and fewer women and many more men.

Sometimes the imbalance of power is so extraordinary that people are noticeably shaken when they see the figures. The most powerful people in most companies are the CEO and the Finance Director. In the 350 biggest Companies (the FTSE350) there are 700 such positions. Only 34 of these posts are held by women and over $95 \%$ of these powerful jobs are held by men.

This imbalance of power does not just occur in private companies. In local government there are many women Councillors, but when it comes to the most powerful position of all: the Council Leader, we found that men outnumber women by about seven to one. We uncovered a similar pattern in the professions and in our institutions. The twelve most powerful judges in Britain sit in the Supreme Court and only one is a woman. Charities and the Arts are often thought to be women-friendly, but men heavily outnumber women as Chairs of Trustees and as Directors. We were shocked by some of the things that go on in our great orchestras. 
We struggled to find sectors where women have a dominant position. The one exception seems to be in primary education where women occupy about $71 \%$ of the headships. Move into secondary education, and men are once more in control, as they are in further education and in the universities.

Is it getting any better? If it is, the progress is glacially slow. We interviewed Brenda Hale, that solitary woman on the Supreme Court, and she was not encouraging. "I am disappointed that in the ten years since I was appointed not one among the thirteen subsequent appointments has been a woman.”

In a better world, this unfairness would be universally recognised and the need for remedial action would be self-evident. However, and surprising though it may seem, a significant number of men (and a few women) do not regard increasing gender equality as a high priority. They question whether it really matters if men hold almost all the senior positions and very few women get to the top. So, in Man-Made, we spell out the reasons why reform is so urgently necessary.

\section{The Business Case}

When Lord Davies began his task of increasing the number of women in Britain's boardrooms, he decided to focus on what he called the "Business Case" for appointing more women. At a Conference in Sheffield we listened to him describing his initiative and we were surprised that in a half hour speech he never once used the words 'equality', 'fairness' or 'justice'. Since the current imbalance of power seems to us to be self-evidently unfair, we asked him why he appeared to disregard these issues. He explained that he had to take account of the views of his audience. Davies had to catch the attention of the men who sit in Britain's boardrooms and control senior appointments. Change would only come if he convinced them that it was in their interest to appoint more women. His tactics were based on the belief that these powerful men would perhaps listen to arguments about commercial advantage but would give little attention to someone 'nagging on about inequality'. So he set about demonstrating that companies with women in the boardroom would perform better than companies with all-male boards. During the whole period of his Government-backed initiative he never stepped outside the narrow confines of this Business Case.

As outlined by Davies, much of the Business Case is perfectly reasonable. Choosing top people from all the population, rather than from the half which happens to be male, immediately doubles the talent pool. Recruiting people with better brains means more ideas and more innovation. Having both men and women in boardrooms means that decisions are likely to be better scrutinised than if only the life experience of men is brought to the table. Recent research also suggests that companies with both women and men at the top are likely to be more prudent and take fewer excessive risks than all-male boards. There is even a suggestion, so far unproven, that companies with women on the board have a better profit record.

However the problem with this Business Case is not with what it claims to deliver but what it chooses to ignore. Basing the case for appointing more women Non-Executive Directors on the proposition that they will make companies perform better might have some validity but it is narrow-minded in the extreme. We argue in Man-Made that the gaining of some small commercial advantage is far less important than giving everyone in Britain: female or male, the same opportunity to fulfil their potential and get to the top. Somewhere in the policy discussion, the enthusiasts for the Business Case seem to have forgotten that politicians of 
every Party say they want Britain to be a more equal society. The achievement of that noble aim should be the driving force for reform.

Unfortunately this argument is often brushed aside. There are many people in senior positions in Britain who, after a peremptory expression of regret, will insist that the problem in our society is not that women are treated unequally but that women do not take advantage of the opportunities that are available to them. "They are less ambitious than men; they do not apply for the jobs; they don't want to work the long hours; they have other priorities; they want to give more time to their families." There is a lengthy catalogue of overlapping arguments, many listed in self-help books, suggesting that women have only themselves to blame. It is argued that if only women tried harder, or if they were more ambitious or were more willing to promote themselves, all would be well.

\section{The unhelpful legacy}

In Man-Made we examine whether it is the women who need fixing or whether the problem lies in an unfair system. We conclude without reservation that Britain has a severe cultural problem. We have a society that awards continuing advantage to men. It is that system and not the women that needs to be fixed.

We examine the causes of Britain's cultural bias. Our analysis begins with an important observation that is rarely made. Our system of government, our professions, our companies, our institutions and almost every aspect of British society was fashioned by men for the convenience of men. This happened mostly during the nineteenth century when women had no vote, few legal rights, very little power and where married women could own no property. In a case study we tell the story of one of our biggest companies, Shell UK. Founded by a man, managed almost exclusively by men and, as a result, Shell UK nowadays forms a comfortable network in which men can flourish. Some women have recently got close to the top and there are women Non-Executive directors but the Shell Management Board, where so much of the power resides, is exclusively male. In this company, as in most organisations, women have to fit into a system and deal with a culture that they had no part in creating.

Most organisations have been structured to suit men: careful distinctions of status between layers of hierarchy with governing bodies that are large and formal. At the top, there are long attendance hours with little time for family. This pattern of work reflects a conviction that the job must take precedence over every other obligation; any request for flexibility is regarded as showing a lack of commitment. A mountain of evidence demonstrates that such man-made structures do not work very well and plenty of women have told us that they are uncomfortable in organisations with narrow and inflexible systems of command and control. Nevertheless, to be successful, women have to find a way to fit in. Most of the interviewees told us that, because, as women, they are regarded as outsiders, they are under constant pressure to prove themselves, and that usually means working harder than the men.

The nineteenth century is a long time ago but Man-made is full of examples of how the customs and attitudes of that distant period maintain a grip on our lives. The House of Commons is laid out like a gentleman's club. Our great institutions are determinedly male. The Institution of Civil Engineers has had 151 Presidents: 150 men and just one solitary woman. Sometimes the results are bizarre. University teachers are called Fellows even when they are women and their female students study for degrees that make them into Bachelors or Masters. 
The cultural legacy has an even deeper significance. From the cradle we are taught that men are the doers and the leaders and that the role of women is to help and support. Anyone who doubts that truism should try to buy a birthday card for a child that shows a girl who is active and in control. Indeed the stereotyping is so strong that many men find it difficult to envisage a woman in a leadership position. We lost track of the times we were told about high-profile women who had been mistaken for catering staff. This happens so often that one woman says she keeps a business card handy to thrust at any man who thinks she is there to serve the canapés.

Women in our culture are expected to be nice, helpful and obliging. Leaders on the other hand are expected to be tough, decisive, dominant and even domineering: the stereotype of the alpha male in all its rugged arrogance. That is certainly an old fashioned and inappropriate image but it is still embedded in our national consciousness. We were told about one particular woman who was thought to lack leadership qualities because she "consulted too much". That was never a criticism that was levelled at the autocratic Fred Goodwin during his disastrous time as Chief Executive of RBS.

This conflict between what is expected of a "normal" female in our society and what is expected of a leader creates a Catch 22 problem for ambitious women. If a woman appears helpful and supportive she may well be liked and valued but she will not be regarded as a candidate for promotion. On the other hand if she starts behaving like an archetypal male leader, she may climb the career ladder but she will almost certainly be intensely disliked. Tough and decisive men are admired; tough and decisive women are liable to be labelled as hard and unfeminine. The cultural stereotyping has an iron grip.

\section{Looking the part}

Because Man-Made is written by both a women and a man, we can contribute very different experiences. A man knows, in a way that no woman can, exactly how some men speak about women in all-male company. When no women are present, the tone is often sexist and the jokes are often insulting. From time to time the curtain is pulled aside and women are allowed to see how some men regard them. John Inverdale had just commentated on the Wimbledon Tennis Final won by Marian Bartoli when he was told that she intended to retire. "I am not sure what she can do next. After all she is no looker", was his comment on her future prospects. When viewers complained he "explained" that he had been misunderstood. In mitigation he added that he had been suffering from hay fever at the time.

The BBC never censored Inverdale for his rudeness, and he kept his job. So did Richard Scudamore, Chief Executive of the Football Premier League, after his emails were hacked and he was found to be assessing women on the basis of their desirability as sexual objects. He often referred to them as "gash" or by some other obscenity. Several people came to his defence. We were told that Scudamore is not sexist and the offending emails were just aberrations. Regrettably this sort of behaviour is only too common. One of the saddest features of our society is that men feel able to comment, often in intimate detail, about how women look and whether they are sexually desirable.

Although most of this offensive examination takes place in private, every woman knows that not only is she expected to behave in a particular way but she must also be very careful about her appearance. The pressure starts early and persists throughout a woman's life. Little girls are told how important it is to be pretty. Teenagers are surrounded by adverts that promote a particular and, for most girls, an unattainable body shape. Women of all ages are bombarded 
with advice on their make-up, hairstyle and, of course, on the desperate need to be slim. In Man-Made we quote research that demonstrates the extent of body shame and shows just how damaging it is to women's self-esteem. Men and women are judged very differently. Men are allowed to go grey without comment but when Mary Beard, the well-known academic, appeared on television with long grey hair, the social media was filled with criticism and abuse.

Almost every woman we interviewed talked about the importance of appearance and the burden it imposes. Our interviewees suspect that many men still judge women more by how they look than by their ability. Indeed some successful women told us that men do not start listening to what a woman says until they have sized her up and decided whether she is attractive or not. There are traps everywhere. An ambitious woman must never appear sexy or she will be the subject of gossip but she must never appear drab because she will be ridiculed or, worse still, publicly pitied. So she has to find the right way to look and, without many role models to emulate, this is easier said than done. As one woman told us, searching for the right style takes up an awful lot of brain space.

\section{Surprises}

The interviews produced many surprises, some unwelcome. We were alarmed by the sexual harassment that some of the women had suffered. A number of the incidents are truly appalling. Most were mentioned, usually with great reluctance, almost as an afterthought. But it was clear from how the incidents were recalled that they had a deep effect on every woman who had suffered.

Even more prevalent were the stories of the relentless low level sexism still encountered by many women: the patronising comments, the jokey suggestions and the breezy assumption that in many respects women are just less capable than men. The constant pressure from a myriad of unwanted remarks was memorably described by one woman as "like water torture".

Discrimination takes many forms. The gender pay gap is well known but we were surprised to find that the official figure produced by the Office of National Statistics (ONS) is based on a comparison that significantly understates the extent and importance of gender pay differences. The ONS figure is about $10 \%$. A more representative figure is double that.

We uncovered many examples of promotion denied and of opportunities constrained. One woman in banking said that she and her female colleagues would often get onto the short list for a top executive position but rarely got the job. "We always seem to come second or third". Sometimes women seem to be ushered away from the most powerful posts or find that the men are given leadership of the most prestigious projects. After that happens a few times, the temptation is to move on and we found that many organisations suffer a substantial loss of talented women. It is not yet as bad as in the US, where the attrition of middle ranking women is so great that it has been called a national crisis, but in the UK the problem seems to be increasing.

\section{The baby question}

The moment when most women discover the full extent of the unfairness in our current system is when they have their first child. One woman reminded us that "the baby question" has never been resolved. Most organisations still seem to expect the "normal" career to be unbroken. Maternity leave is looked on as a significant business inconvenience rather than as 
a normal fact of life. Some women told us that the best time to have children is before a career takes off; others said that it is best to wait until a career is established. The truth is that, because of the way the world of work is organised, there is no right time. Whenever a woman is absent, men are being promoted and leaving her behind.

Childbirth brings many problems. Mothers are paid less and promoted less. Childcare can be a nightmare. Many women noticed that, once they had children, they were no longer regarded as reliable employees. Some said the best way to avoid unfair treatment is not to mention their children: in effect to make them "invisible". The most worrying comment came from a woman who had chosen not to have children: she said that she was sure that she would not have achieved the same success in her career if she had decided to be a mother. One of the great failures of our society is that our power structures and our systems of work do not take proper account of the self-evident fact that most women bear children.

\section{Enforcement}

What should we do about this complex of problems? Man-Made is not just concerned with describing the source, interaction and severity of the injustice in our society; our aim is to find remedies and solutions. People talk about the smashing the "glass ceiling" but TUC General Secretary Frances O'Grady sees things differently. She says, "Never mind the ceiling, the whole house needs to be rebuilt from the skirting boards to the roof." We are convinced that because so many of the attitudes, customs and practices that we have identified are longstanding and deep-rooted, only a thorough-going process of reform will be successful. We need to change our culture. Quick-fix solutions do not work.

So the last part of Man-Made is about how we can achieve equality, not in the 70 or 100 years that are predicted if we let current policies run their course, but in a single generation. In Chapter 11 of Man-Made we set out an extensive programme of specific reforms.

The starting point for any thoroughgoing process of reform is easy to identify. Those important laws of the 1970s: the Sex Discrimination Act and the Equal Pay Act, were intended to remove the two greatest injustices suffered by women. The two Acts of Parliament were significant in declaring public policy and changing some management practices but unfortunately they have not delivered the fair treatment that they promised. The reason is simple: the two Acts have never been properly enforced.

A woman who feels that she has suffered discrimination must take her case to a Tribunal. At first sight that seems wonderfully reasonable. In practice it usually results in a horrendous experience for the applicant. Tribunals were meant to provide informal justice in a relaxed atmosphere but that hope has never been fulfilled. To be successful, the woman applicant has to challenge her employer in public and that can be traumatic. The employer's lawyers will most likely disagree with her version of events, cross-question her about the details and suggest that she is either mistaken or telling lies. Tribunals meet in public and the newspapers often report cases. The appellant has her appearance scrutinised and prurient remarks are frequently made about how she dresses and carries herself. All this is extremely distressing and the fact that the woman's name becomes public knowledge means that the personal damage stretches into the future. Human Rights Barrister Helena Kennedy warns women about the risks of taking discrimination cases. "You may be a victim... even if you win the case. You may well be seen as a trouble maker by future employers. It might well be a pyrrhic victory." 
We believe that it is ludicrous to rely on the bravery of individual women to enforce major social legislation. The task of enforcing the law should be transferred to a public agency.

\section{Transparency}

Man-Made reveals that much unfairness and discrimination in Britain's workplaces tends to be hidden and is the result of informal practices that are neither exposed nor explained. Organisations are expected to treat men and women equally but it is very difficult to discover how their policies work in practice. Companies often boast about their commitment to equality for women but they rarely publish the information which would allow their claims to be tested. We argue that companies and other organisations should be required by law to be open and transparent about gender pay differences and about the positions and status of men and women in their employ. Reports should be up-to-date, regular and published over the name of the Chief Executive.

\section{Positive action}

The British Government believes that voluntary action will increase the number of women in senior positions and has ruled out changes in legislation. Unfortunately for the supporters of voluntarism it is very difficult to find an example anywhere in the world where the voluntary approach has worked. Indeed more and more progressive Governments now accept that government intervention is necessary and desirable. Norway led the way by introducing a quota system that requires the boards of large companies to include at least $40 \%$ women (and at least $40 \%$ men). The rest of the world is following. The British Government's opposition to quotas is looking more and more like an out-dated and minority position.

Whenever quotas or other forms of direct government action are contemplated, the objection is usually made that senior positions must be filled on merit and that taking positive action to increase the number of women conflicts with the merit principle. Therefore, in Man-Made, we examined the issue of merit very carefully.

At first sight it is difficult to believe that men are better equipped than women to make good decisions. Girls tend to outperform boys at primary and secondary school and more women than men gain university degrees. But it was when we examined exactly how senior positions are filled that the extent of injustice in the present system was exposed.

Are top jobs filled on merit? The answer is: very much less often than is usually claimed. Almost all senior appointments in the private sector are made informally and without due process. Only 1\% of positions on boards of FTSE100 companies are actually advertised. Some vacancies are filled from lists produced by Head-hunters but rather more are filled from friends and personal contacts. This means that most women (and most men) do not even know that a vacancy exists until after it has been filled.

\section{Career breaks}

We make a series of other recommendations and they would all move equality a little closer. But we soon became aware that the present structure of careers favours men so strongly that, unless that is changed, women would remain at a disadvantage. So our final recommendation is the most radical: we aim to disrupt the notion that the normal career path of people in Britain is linear and unbroken. To do that we need to make breaks in work: that are so 
necessary to women and for which they are so heavily penalised, into a normal feature of everybody's working life.

Fortunately there will soon be an opportunity to make the necessary change, bringing relief to women and, we are glad to say, better career prospects for men. Girls born today will probably live to 100 and boys will not be far behind. So we will face a working life not of 40 years but of 60 years and perhaps even longer. This explosion in longevity means that the world of work has to change; few people can contemplate 60 years of continuous graft without a desperate lowering of the spirits. Even the most unimaginative politician will recognise that this is not a prospect that can easily be put before the British people. At the very least we will need changes to make such a long working life tolerable. We suggest that public policy goes much further, and that we take the opportunity to design a new system of work that will make our lives more equal and more fulfilling.

We believe that a key element in that new system should be an entitlement for each individual to take paid career breaks periodically through their working life. In our proposal each of those breaks should be for a maximum of three years: long enough to take an extensive period of training or a full university course.

To ensure that the entitlement is universal and does not inflict unreasonable costs on employers, the payment would have to come from the state. That probably means that, although our motive is different, the change would have to be justified in economic terms. Fortunately that is not difficult. As working lives grow longer and the pace of technological change accelerates, a continuing cycle of training and retraining will be an economic necessity. For the development of talent and innovation people must be given a second and third chance at higher education. In an extended working life people will need periods of rest and reflection and the chance to change direction, to try new things and to move into a new career. By including childbirth and childrearing in the career break system, women will have more flexibility to plan their families without damaging their prospects at work. Men will have a genuine opportunity to contribute to child-rearing without ruining their careers.

Paid career breaks will make the world of work fairer for women and more congenial for men. Careers will become more varied with fresh starts and new opportunities. The linear career will be banished to the history books, fewer men will be trapped in careers that have lost their appeal and women will no longer find that after childbirth they are always playing catch-up.

\section{Innovation and talent}

Our full programme of reform amounts to a substantial change in society and a transformation in the world of work. For the reasons we have explained, we base our justification on the principles of equality and fairness. However our programme can also be regarded as achieving the modernisation of systems that are outdated and are no longer fit for purpose.

Over-powerful Chief Executives, top down control and hierarchical management remain the organisational characteristics of most companies in Britain. More than a decade ago the American academic Rhona Rapaport and her colleagues carried out a detailed examination of what such a structure means in practice. Their conclusion is that it is normally extremely damaging. The man at the top usually tries to control too much and, as a consequence, the talent of other people in the company is wasted. Catching the eye of the top man is a good way to gain recognition, so individual success and self-promotion come to be regarded as more important than collective effort. The routine and unglamorous work of support staff, 
most of whom are usually women, rarely catches the attention of the top man and, as a consequence, their work is routinely undervalued.

Wasting talent means that innovation is stifled. The concentration of power at the top of organisations distorts priorities. Any initiative launched by the top man is given greater importance than other work, even if that work is very important. Employees at lower levels in the hierarchy may have great ideas but they must be very careful to ensure that those ideas do not conflict with, or undermine, the convictions or prejudices of the top man. Some of those prejudices can be both startling and stultifying. We were surprised to be told by one female senior executive in the retail sector that her boss dismissed organic products as "a passing fad".

We interviewed Lesley Wilkin, the Managing Director of Hay in the UK and Ireland. She is not impressed by macho posturing and says that good leaders must be adept at "managing the complex relationships with the many stakeholders" of an organisation. This is not a new conclusion. Annie Pye, from the University of Exeter says that more than a century ago sociologists such as Georg Simmel were studying the importance of the social networks through which people operate. Annie Pye's own research demonstrates that successful leaders operate, "at the centre of a web of relationships". And the modern leader has to foster diversity in appointments and diversity in opinion because these are the necessary attributes of an innovative organisation.

This more modern view of leadership, within organisations where power is less concentrated and structures are less hierarchical, would make work more satisfying for most women and, we believe, for most men. If structural reform could be accompanied by changes in attitudes which recognise that men as well as women might move from full-time employment to parttime and back again, we would be creating not only the conditions for greater equality but starting to build a society which values family relationships and friendships as much as it lauds ambition and financial success. That might also become a world where looking after children and elderly dependents is recognised as the obligation of all humanity and not just of the half that is female.

\section{Political Pressure}

Will any Government elected in the next few years have the foresight and determination to adopt such a radical programme? A culture change is needed, and modern governments seem to have lost the appetite for reforms on the scale that is necessary to make our society more equal and our lives more fulfilling. It also has to be recognised that a radical programme of reform will face substantial opposition. Very few of the top men in our society seem attracted to the idea that they should share some of their power and some of their wealth.

Our best hope is that enough of the women who suffer the injustice of our unfair society might decide to put politicians under the sort of sustained pressure that we last saw 40 years ago. Before that happens, a dilemma will need to be resolved. Women want equality but we found that many, including younger women, dislike being called feminists. The myths of braburning and man-hating still make women hesitate. So, at the end of Man-made, we speculate about whether the new generation of women activists can rehabilitate feminism and mobilise the power to change the out-dated culture of Britain.

Success will bring many rewards and not just to women. Our radical programme would help men to escape from the confines of a narrow masculinity and live in a society that honours them as much for their compassion as for their toughness. For women, much more is at stake. 
If we allow Governments and our powerful organisations to take no effective action, our offspring will inherit the inequality that we have tolerated for so long. Without a new and more determined programme of reform, our great granddaughters will still be paying the price of our failure in the last years of this century.

\section{About the authors:}

Eva Tutchell

Consultant and writer on education and gender issues.

evatutchell@hotmail.com

John Edmonds

General Secretary of the GMB trade union. He is a Visiting Fellow at King's College London, and a Visiting Professor at Durham University Business School.

johnedmonds1@hotmail.com 